\title{
The tuberous sclerosis syndrome: clinical and EEG studies in 100 children
}

\author{
G. PAMPIGLIONE AND E. J. MOYNAHAN
}

Departments of Clinical Neurophysiology and Dermatology, The Hospital for Sick Children, Great Ormond Street, London

SYNOPSIS The evolution of the early clinical and EEG features in 100 children who developed the tuberous sclerosis syndrome is discussed with particular emphasis on individual variability of epileptic manifestations, skin changes, and mental defect. There were 61 boys and 39 girls. Seizures of various kinds occurred in 98 and in the first 2 years of life infantile spasms were a prominent feature (69) with a partial overlap of other kind of seizures (75). Mental defect (88) and poorly pigmented areas of the skin (77) were already detectable in the first 1 to 2 years of life, while fibroangioma of the face (adenoma sebaceum) (77) and intracranial calcifications (35) became increasingly apparent after the age of 2 to 4 years. The EEG abnormalities tended to be gross in the first 2 years of life, but their subsequent evolution was towards multifocal alterations and some areas of relatively better preserved rhythmic activity. The evolution of the various skin lesions did not run parallel either with that of the clinically detectable seizures or with the appearance of intracranial calcifications.

Tuberous sclerosis, sometimes called BournevillePellizzi's disease, is still considered a somewhat rare condition not only in most textbooks but also among practising neurologists and paediatricians. The term 'epiloia' was introduced by Sherlock in 1911 to indicate in a single word the mental defect, the epileptic seizures, the adenoma sebaceum, the nodular sclerosis of the cerebral cortex, and the tumours in the kidney and other organs: this term is now rarely used because few people remember its meaning and it is not a very helpful synonym.

From the work of Critchley and Earl (1932), Borberg (1951), and Hallervorden and Krücke (1956) and their reviews of the early literature, there is no doubt that in this genetically determined disease a large variety of lesions may develop in various organs giving rise to a medley of complex syndromes. For this reason in the present study the term tuberous sclerosis syndrome (TSS) is used to cover the many possible manifestations of this peculiar disorder.

In most of the published papers the number of

(Accepted 20 February 1976.) cases of TSS reported in children is relatively small. The present study of 100 children who developed TSS describes the evolution of some of the early clinical and EEG features with particular emphasis on individual variability of epileptic manifestations and skin changes.

\section{METHODS}

Each of the 100 young patients ( 61 boys and 39 girls) had been admitted to the wards of the Hospital for Sick Children for periods of a few days to many weeks under the care of various members of the staff. Information about family history, the events at birth, and the evolution of symptoms which led the patient to the hospital was often amplified by further retrospective inquiries when the baby or child was first referred to the Department of Neurophysiology. While the initial referral was often in the first few months of life, the diagnosis was established only after an adequate follow-up. The neurophysiological studies were repeated weeks, months, or years later with a total of 525 EEG and allied investigations during the period 1957-71.

Some of the data were accumulated from follow-up studies of a group of children originally referred because of the syndrome of infantile spasms with 
motor and mental retardation. Other cases had been referred because of other types of seizures or because mental defect was the main cause for concern. Either initially or at follow-up the skin was carefully examined with particular attention to lack of pigment at any site on the trunk and limbs and to the presence of fibroangiomatous lesions on the face. The age at which these and other skin lesions were first recognised was noted. Whenever possible, black and white as well as colour photographs of the child and sometimes of one or the other parent were taken for further documentation of the range of skin lesions in the family.

The EEGs were taken with a uniform technique with silver-silver chloride electrodes stuck on the scalp with collodion, their contact resistance being lowered to about $5 \mathrm{k} \Omega$ through appropriate conducting jelly. The placement of the electrodes was based on measurements fi om bony landmarks (Pampiglione, 1956) and the EEG apparatus was eight-channel Offner-Beckman. Photic stimulation was carried out as part of the test but hyperventilation was often impossible, not only when the children were very young but also when they grew up into older children grossly retarded and unable to co-operate. In particular circumstances additional studies were carried out and the techniques of poly-electromyography (Pampiglione, 1966), electroretinography, and visual evoked responses (Harden and Pampiglione, 1970) have already been published.

Most of the patients with skin anomalies of various kinds which had been recognised for the first time in the EEG Department were re-examined by other colleagues and the dermatologists. Some of the patients who had been photographed in the initial phases were photographed again some years later.

\section{RESULTS}

The selection of the 100 children was based on the presence of at least three (usually more) of the following phenomena: (1) seizures of various kinds including infantile spasms; (2) mental defect; (3) fibroangioma of the face (adenoma sebaceum); (4) non-pigmented or hypopigmented areas of the skin of the limbs or trunk; (5) neuroradiological evidence (either the presence of intracranial calcifications or appropriate alterations revealed by pneumoencephalography); (6) other manifestations, such as retinal phakoma, rhabdomyoma of the heart, peau de chagrin, subungual fibroma, etc. The distribution of clinical phenomena in cases followed up from a minimum of two years to a maximum of 15 years is shown in the Table.

\section{T A B L E}

TUBEROUS SCLEROSIS SYNDROME (GOS 1957-71)

\begin{tabular}{lc}
\hline Main clinical features & (No.) \\
\hline Mental subnormality & 88 \\
Fibroangioma (adenoma sebaceum) & 77 \\
Non-pigmented areas & 77 \\
Seizures other than infantile spasms & 75 \\
Infantile spasms & 69 \\
Intracranial calcifications & 35 \\
(plain skull radiograph) & 24 \\
Peau de chagrin & 20 \\
Retinal phakoma & 20 \\
Other miscellaneous lesions & \\
\hline
\end{tabular}

Main clinical features in 100 children (61 boys and 39 girls) who developed TSS during the follow-up period 1957-1971, with considerable overlap of signs and symptoms. Seizures had not been reported or observed in two children. Skin lesions of one or more types had been found in all patients.

The occurrence of infantile spasms (massive brief flexion or extension of the limbs, trunk, and head lasting from a fraction of a second to two to three seconds and occurring in series, separated by intervals of a few seconds, for periods of several minutes) has been contrasted with the occurrence of other types of seizures often witnessed at the time of the EEG investigations (Fig. 1). About one in five of the children

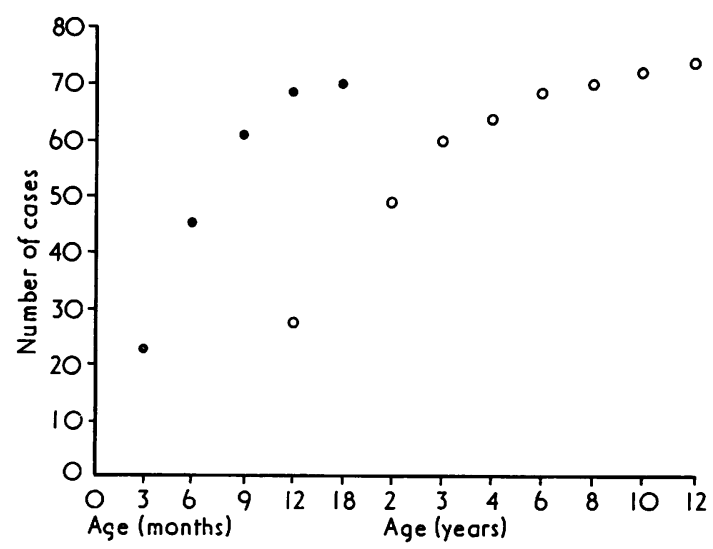

FIG. 1 Tuberous sclerosis syndrome (GOS, 1957-71) 100 children (61 boys, 39 girls). Age at which infantile spasms $(\bullet, 69)$ and/or other types of seizures $(\bigcirc, 75)$ were first noticed, with a large overlap. 
presenting with infantile spasms also had other types of seizures in the first year of life. By the age of 2 years the spasms had disappeared, while focal or multifocal attacks persisted with considerable individual variability. Episodes of prolonged and repeated seizures with little if any recovery in between occurred in six children during the follow-up period. No follow-up could be made during later adolescence or adult life to see whether other forms of seizures might occur later on in life, or how commonly all attacks might cease altogether.

The age at which mental defect (IQ below 70), poorly pigmented areas of the skin, and fibroangioma of the face (adenoma sebaceum) was noted in the course of follow-up is shown in Fig. 2. Of course, some of the skin lesions, especially the poorly pigmented areas (as well as the mental defect), may have been present for a longer period though not previously recognised or not recorded in the clinical notes before the patient was referred for either EEG or dermatological investigations. It was interesting to notice that in nearly one-third of the children the characteristic fibroangiomatous lesions of the face could be recognised by experienced observers by the age of 2 years though usually becoming

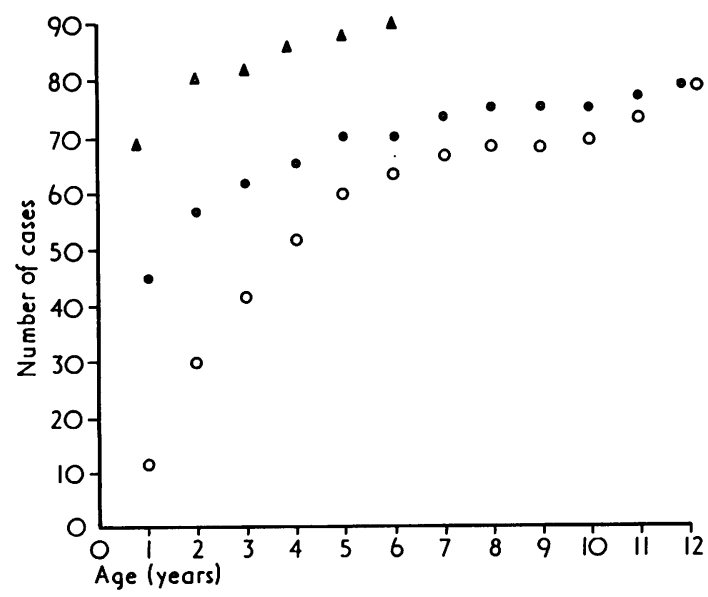

FIG. 2 Details as in Fig. 1. Age at which mental subnormality $(I Q$ below 70$)(\triangle, 88)$, poorly pigmented areas of the skin of trunk and limbs $(0,77)$, and fibroangioma of the face (adenoma sebaceum) $(0,77)$ were first noticed. more obvious by the age of 4 to 10 years. It is not generally appreciated that the dilatation of the vessels, the vascular element of these lesions, may be transient at first.

Chest radiography and radiological studies of the bones (hands and feet) would have offered additional clues to the diagnosis of TSS but were not carried out in these 100 children. Plain radiography of the skull revealed intracranial calcifications in 35 cases but serial studies were not carried out; probably in adult life the intracranial calcifications may reach the figures of $51 \%$ quoted by Lagos and Gomez (1967) or $60 \%$ by Zaremba (1968). Pneumoencephalography was performed in only 49 cases at the discretion of the physician or surgeon in charge of the patient: irregularities of the ventricles or definite nodules attributed to 'tubers' were detected in 31 of these patients, while doubtful features were found in four. In 11 no abnormality was found. Some atrophy was seen in the remaining three cases.

The EEG features were complex in type and displayed considerable variability throughout thefollow-up period. Forty-six per cent of the patients had their first EEG in the first year of life and the subsequent examinations were carried out at somewhat irregular intervals from? a few days or weeks to some years. EEG alterations in the babies were usually gross, often of the type described as hypsarrhythmia (see Gibbs and Gibbs, 1952; Friedman and Pampiglione, 1971). In those patients in whom the EEG changes were minimal at the time of the first referral, the EEG abnormalities tended to increase during sleep though this did not take place in every patient.

Over the last 15 years the administration of ACTH to babies with otherwise intractable seizures has modified the natural course of many groups of diseases, including the infantile spasms syndrome, in a complex way. In 30 of the children of the present series who had been treated with ACTH before the end of the first year of life it was found that the discharges seen in the EEG had completely disappeared with an increase in lower amplitude slow activity within a few days or a week from the beginning of ACTH. However, in another group of 16 infants there was only a partial diminution of EEG alterations after administration of ACTH, with persistence of 
focal (usually multifocal) EEG abnormalities. With the passage of time, months or years after the end of the last or only course of ACTH, normal rhythmic EEG activity tended to appear in several areas of the brain, while irregular slower waves and sometimes discretely focal spikes appeared in other regions (see Fig. 3).

After the age of 4 to 6 years there were periods of weeks or months in which, without known triggering factors, the discretely focal EEG abnormalities would change in distribution, or markedly increase and a variety of clinical seizures might occur. Twelve patients displayed a progressive general deterioration, with uncontrollable seizures, in whom the EEG showed prolonged episodes of $1 \frac{1}{2}-2 \mathrm{~Hz}$ waves mixed with irregular spikes and sharp waves, often more evident in the frontal regions than elsewhere (so-called Lennox syndrome). In seven patients the EEG abnormalities disappeared altogether during the follow-up period. In five patients with symptoms and signs suggesting an expanding intracranial lesion large amplitude irregular focal slow waves in the EEG tended to indicate the area where the main distortion of vessels and oedema were present. Either partial or total neurosurgical removal of the tumour was carried out.

In patients with intracerebral calcifications seen in the radiograph the multifocal EEG abnormalities were usually modest and only infrequently localized near the calcification. In these children any clinically focal seizure was often more closely related to the areas of greater EEG abnormality than to the areas with calcified nodules. While serial radiography of the skull over the years was not carried out in the great majority of our children, it was interesting to note that single or multiple intracranial calcifications could be detected in at least five children in whom pneumoencephalography did not reveal any irregularity of the ventricular profile.

\section{DISCUSSION}

In addition to sporadic observations published as anatomical curiosities in the second half of the last century, the clinical and anatomical relationship between idiocy, epilepsy, and a patchy sclerosis of the brain was recognised by Bourneville in a series of papers between 1880 and 1900: he gave it the name of 'sclérose tubéreuse'. In a clinicohistological study of idiocy, Pellizzi (19001901) was the first to suggest that, in the cerebral lesions as well as in those of other organs, there are groups of cells with atypical morphology and development. He described these changes under the term of 'istoatipia cellulare'. He also stressed the importance of anomalous site (heterotopia) orientation and shape of neuronal elements. This was at the time a new concept but his important contribution was soon forgotten.

Among other often forgotten contributions are those of Dawson (1954) on the pulmonary aspects of tuberous sclerosis and of Berland (1953) on the bony lesions commonly seen in this syndrome.

The early clinical features of TSS in infancy, especially the description of the early seizures, have been largely neglected in the literature including such reviews on tuberous sclerosis in infancy as Debré et al. (1952), Borberg's monograph (1951), and Wilson's textbook (1940). However, one of us noticed that the syndrome of infantile spasms (originally described in 1841 by Dr W. J. West in his own son) had probably occurred in six of 12 children who later developed TSS (Della Rovere et al., 1964): this finding was confirmed by Gastaut et al. (1965), and was treated more fully by Pampiglione et al. (1968). The prognostic importance of non-pigmented areas of the skin in babies with the infantile spasms syndrome was clearly described by Gold and Freeman (1965) and confirmed among others by Crichton (1966), and recently by Fois et al. (1973).

The follow-up of each child was not uniform, as some had been referred soon after the onset of symptoms, while others were referred from other hospitals months or years later. Moreover, the experience gained over a period of 15 years made it possible to recognise pinhead erythematous macules, often transient in the initial phases, which eventually developed into the more obvious fibroangiomatous lesions of the face (adenoma sebaceum). The poorly pigmented areas of the skin, although noticed in several of our cases before 1965 (see Crichton, 1966; Harris and Moynahan, 1966) and even mentioned by Critchley and Earl (1932), were given much more definite diagnostic significance since the appearance of the paper by Gold and Freeman (1965) and were shown to be pathognomonic of TSS 
$\underline{A}$

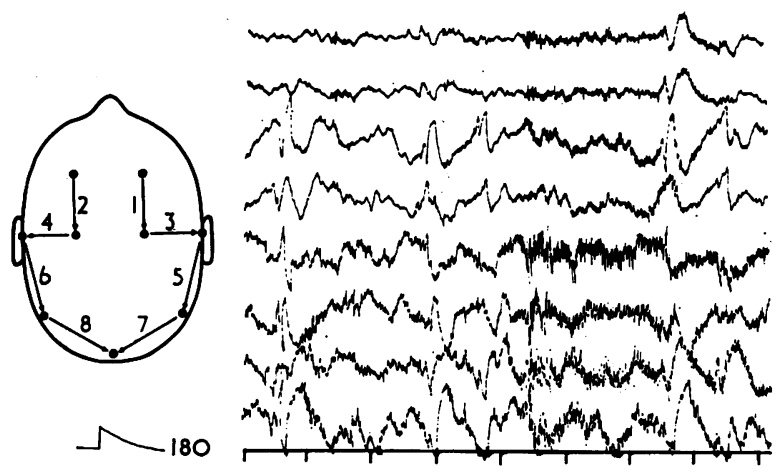

$\underline{c}$

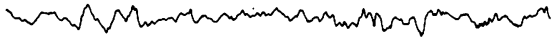

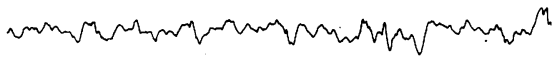

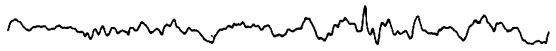

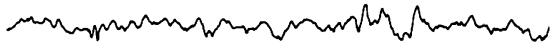

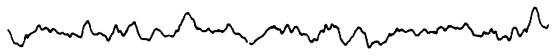

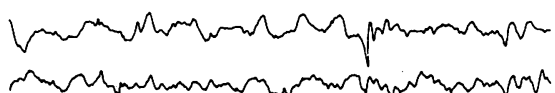

180
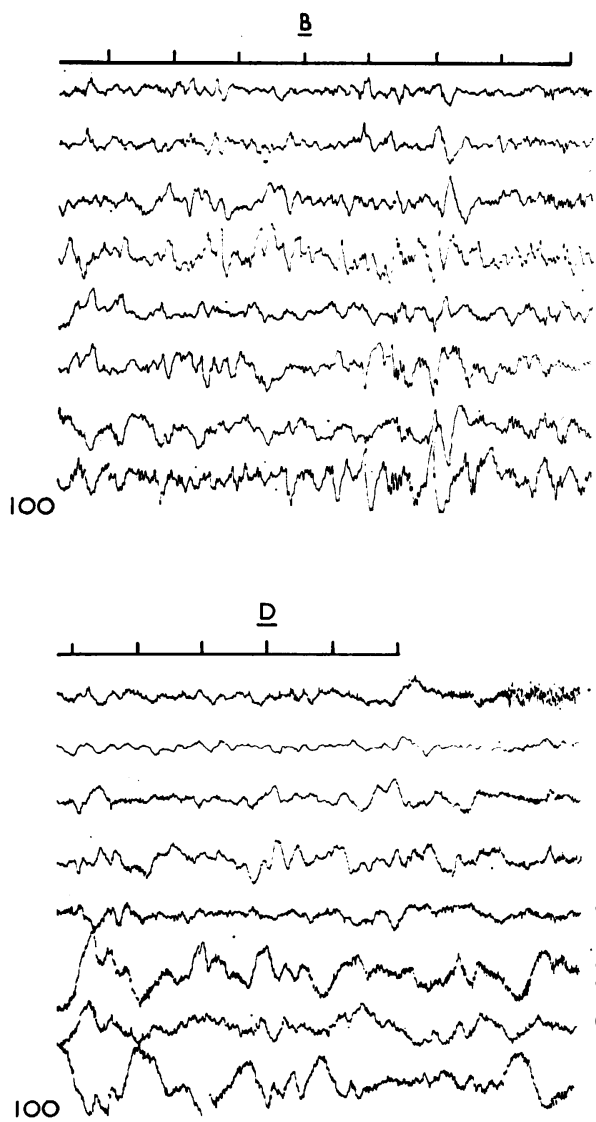

FIG. 3 Evolution of EEG features in a girl who developed the infantile spasms syndrome at the age of 3 months and subsequently other types of seizures. A. At 20 months large amplitude irregular slow activity and multifocal discharges, less marked over the frontal lobes (calibration $180 \mu v$ ). B. At 2 years there is apatchyexcess of irregular slow components more obvious posteriorly, and sharp elements appear focal in the left temporo-occipital region (calibration $100 \mu v)$. C. At $2 \frac{1}{2}$ years a greater number of irregular slower waves are seen with infrequent sharp elements in the left posterior temporal region (calibration $180 \mu \mathrm{v}$ ). D. At 3 years more irregular slow activity over the right frontocentral and left temporo-occipital area (calibration $100 \mu v)$. In this child the mental subnormality was already obvious at an early age, as well as the multiple poorly pigmented areas on the limbs and trunk. Multiple intracerebral calcifications were seen in the skull radiograph taken at 19 months (same child as Fig. 4).

by Fitzpatrick et al. (1968). The large preponderance of patients in whom the mental defect was recognised in the first 2 years of life may be partly due to the inclusion of babies initially referred because of the infantile spasms syndrome who later developed more obvious skin lesions or, in some cases, intracranial calcifications.

The 'non-pigmented' or 'poorly pigmented' areas of the skin of the trunk and limbs were usually multiple and the Wood's light sometimes revealed many more 'white patches' with faint punctate pigmentation, occasionally small of the order of 2 or $3 \mathrm{~mm}$ but usually much larger, as described by Gold and Freeman (1965): the 'ash-leaf shape' was not particularly common (Fig. 4). Their number, shape, and distribution were extremely variable as in the cases reported by Hurwitz and Braverman (1970). In older children it was sometimes difficult by simple inspection and without a magnifying lens to 


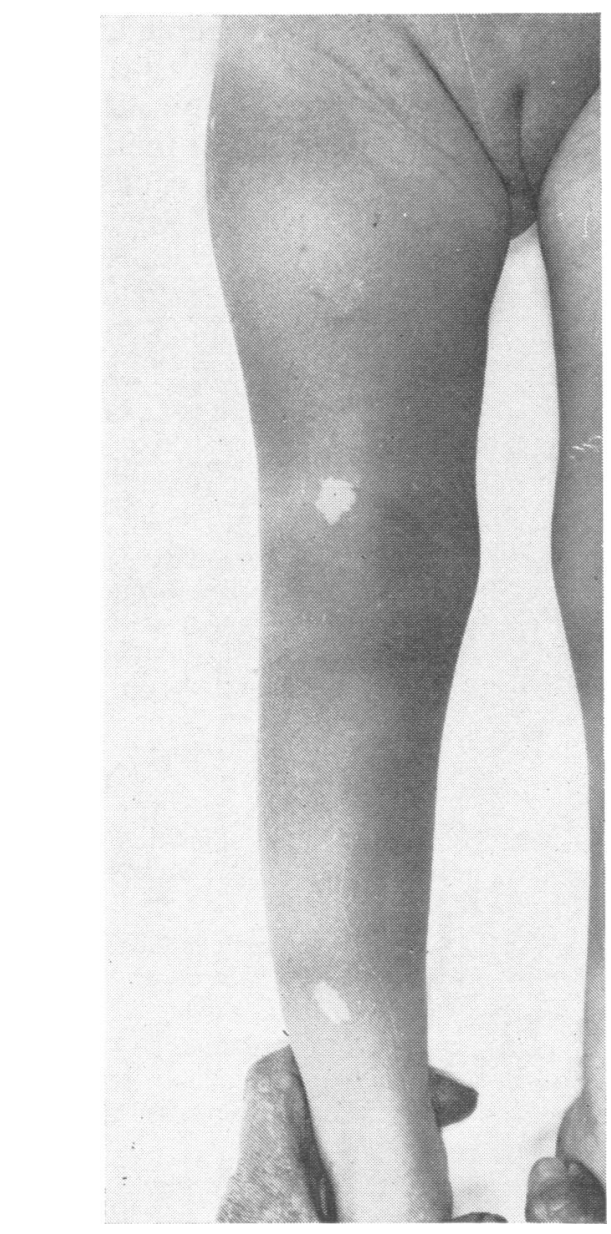

FIG. 4 Poorly pigmented areas of the skin in TSS. Their number, shape, and distribution are variable. In addition to the two more obvious white patches above the right knee and above the right ankle, other smaller hypopigmented areas are present on the right thigh and above the pubis. Tiny white areas are just visible near the knee and the hip.

distinguish these skin anomalies (with a normal epidermis) from superficial scars. It was much easier, therefore, to recognise this type of skin anomaly in babies of a few months old when superficial scar lesions with diminished pigmentation are much less common than in older children. However, histological, histochemical, and ultrastructural studies (Fitzpatrick et al., 1968; Tilgen, 1973; Fischer et al., 1974) make it possible in case of doubt to draw a clear distinction between the poorly pigmented areas of TSS and either scars or vitiligo.

It was interesting to notice in some patients that both the fibroangioma of the face and the poorly-pigmented areas of the skin could change in appearance during long periods of administration of ACTH. This, however, has not been a uniform phenomenon and in some patients these skin lesions did not alter substantially in spite of massive doses of ACTH. While the effect of ACTH upon the EEG of children with infantile spasms (Harris, 1964) is to some extent predictable in nearly two-thirds of the cases (diminution in the amplitude of the traces, increase in slow activity of low amplitude, and disappearance of the multifocal discharges) such EEG changes did not seem to parallel the evolution of the skin lesions. The lack of any close relationship between the extent of the skin lesions and that of the 'cerebral sclerosis' had already been noticed by Brushfield and Wyatt (1926) in 16 institutionalized patients.

The variable and independent evolution of lesions in each organ of the same individual has not been sufficiently emphasised in the literature. The underlying pathological process is not acting uniformly but this is not uncommon in inherited diseases in which a major gene has pleiotropic effects. This would support the original view of Pellizzi (1900-1901) that in this condition atypical groups of cells become capable of atypical proliferation among more normal structures and some of their nodular growth may be indistinguishable from tumours. Little is known about the fetal age at which such disorganization of various tissues may be detected, though Ross and Dickerson (1943) had suggested the fifth or sixth month of gestation.

ACTH, which induces profound metabolic and endocrine changes affecting the whole body, was followed by an equally favourable response (both clinical and EEG) in babies with infantile spasms who subsequently developed the features of TSS and in others who did not develop any skin lesions. This would suggest that treatment with ACTH should not be denied to babies with already obvious signs of TSS.

It was also interesting to notice that the percentage of children developing fibroangioma of the face since the introduction of ACTH 
therapy at our hospital in 1961-1962 did not differ substantially from that of the group of children referred during the previous five years who had not been treated with ACTH. This seems to exclude the remote possibility that ACTH might facilitate the appearance of such skin lesions.

Despite the common origin from the ectoderm of both the CNS and the epidermis, including melanocytes, the remarkable variability in the evolution of skin anomalies seen in children with TSS did not seem to parallel either the degree of mental defect or the severity-or changes in the severity-of the EEG abnormalities. The photographic documentation of the skin lesions in many of the children and many of their parents as well, suggested that 'formes frustes' of TSS may be much more common in the families of babies presenting with the infantile spasms syndrome than it appears from the work of Bundey and Evans (1969). However, our photographic records of members of each child's family are far from complete and systematic work in this field is desirable. The study of a control group to compare with families of the propositi might offer useful information.

There was no constant relationship in our material between the presence and number of poorly pigmented areas of the skin in the first few months of life and the severity of other types of skin lesions in the same child in subsequent years, although there was a tendency for some small areas with pigmentation to develop in the 'white' patches as the patient grew older.

In spite of the wide variety of clinical manifestations in the evolution of TSS some form of seizure had occurred in $98 \%$ of the children of our present series. In particular, the infantile spasms were an early type of seizure in 69 children out of the present series. During infancy it is difficult to predict how many of the babies presenting with these 'spasms' may eventually develop the features of TSS. However, from a recent preliminary study (Pampiglione and Pugh, 1975) this occurs in over $25 \%$ by the age of 4 years.

The occurrence of the symptoms and signs of a cerebral hemisphere tumour is well known both in adults and children with TSS and it occurred in five of the 100 children in the present series. We do not know, however, what proportion of patients presenting with an expanding lesion of the brain may also show some skin lesions of the TSS or, conversely, whether any such skin anomalies might have been looked for in those cases. In an unexpected number of patients with seizures who had a temporal lobectomy (Taylor et al., 1971), careful histological studies have revealed localized cellular features somewhat reminiscent of TSS and not unlike Pellizzi's descriptions (1900-1901). Perhaps TSS in its various manifestations is much more common than is at present suspected.

We wish to thank our colleagues at Great Ormond Street and outside for referring their patients and we are grateful to the Epilepsy Research Fund for their support. The helpful comments of Sir Charles Symonds are gratefully acknowledged. We are indebted to Professor $\mathbf{M}$. Pennacchietti for his help in our search on Pellizzi's papers.

\section{REFERENCES}

Berland, H. I. (1953). Roentgenological findings in tuberous sclerosis. Archives of Neurology and Psychiatry (Chic.), 69, 669-683.

Borberg, A. (1951). Clinical and Genetic Investigations into Tuberous Sclerosis and Recklinghausen's Neurofibromatosis. Munksgaard: Copenhagen.

Bourneville (1880). Contribution à l'étude de l'idiotiesclérose tubéreuse des circonvolutions cérebrales: idiotie et épilepsie hémiplegique. Archives de Neurologie, 1, 69-91.

Bourneville (quoted by Pellizzi) (1889). Idiotie symptomatique de sclérose tubéreuse ou hypertrophique. Progrès Medical, 41.

Brushfield, T., and Wyatt, W. (1926). Epiloia. British Journal of Children's Diseases, 23, 178-185. 254-265.

Bundey, S., and Evans, K. (1969). Tuberous sclerosis: a genetic study. Journal of Neurology, Neurosurgery, and Psychiatry, 32, 591-603.

Crichton, J. U. (1966). Infantile spasms and skin anomalies. Developmental Medicine and Child Neurology, 8, 273-278.

Critchley, M., and Earl, C. J. C. (1932). Tuberose sclerosis and allied conditions. Brain, 55, 311-346.

Dawson, J. (1954). Pulmonary tuberous sclerosis. Quarterly Journal of Medicine, 23, 113-146.

Della Rovere, M., Hoare, R. D., and Pampiglione, G. (1964). Tuberose sclerosis in children: an EEG study. Developmental Medicine and Child Neurology, 6, 149-157.

Debré, R., Thieffry, S., Mozziconacci, P., Bargeton, E., and Ramade, J. (1952). La sclérose tubéreuse de Bourneville chez le nourisson et le petit enfant. Archives Francaises de Pédiatrie, 9, 342-382. 
Fischer, M. H., Fortune, Joan S., and Gerritsen, Theo (1974). Serum proteins and alkaline phosphatase levels in patients with tuberous sclerosis. American Journal of Mental Deficiency, 78, 674-677.

Fitzpatrick, T. B., Szabò, G., Hori, Y., Simone, A. A., Reed, W. B., and Greenberg, M. (1968). White leafshaped macules: earliest visible sign of tuberous sclerosis. Archives of Dermatology, 98, 1-6.

Fois, A., Pidindelli, C. A. and Berardi, R. (1973). Early signs of tuberous sclerosis in infancy and childhood. Helvetica Paediatrica Acta, 28, 313-321.

Friedman, E., and Pampiglione, G. (1971). Prognostic Implications of EEG findings of hypsarrhythmia in first year of life. British Medical Journal, 4, 323-325.

Gastaut, H., Roger, J., Soulayrol, R., and Pinsard, N. (1965). Encćphalopathie myoclonique infantile avec hypsarythmie (Syndrome de West) et sclérose tubéreuse de Bourneville. Journal of the Neurological Sciences, 2 , 140.

Gibbs, F. A., and Gibbs, E. L. (1952). Atlas of EEG, vol 2. Addison-Wesley: Cambridge, Mass.

Gold, A. P., and Freeman, J. N. (1965). Depigmented naevi, the earliest sign of tuberous sclerosis. Pediatrics, 35, 1003-1005.

Hallervorden, J., and Krücke, W. (1956). Die tuberose Hirnsclerose. In Handbuck der spezielle pathologischen Anatomie und Histologie, vol. 13, p. 602. Springer: Berlin.

Harden, A., and Pampiglione, G. (1970). Neurophysiological approach to disorders of vision. Lancet, 1 , 805-809.

Harris, Ruth (1964). Some EEG observations in children with infantile spasms treated with ACTH. Archives of Disease in Childhood, 39, 564-570.

Harris, R., and Moynahan, E. J. (1966). Tuberous Sclerosis with vitiligo. British Dermatology, 78, 419-420.

Hurwitz, S., and Braverman, I. M. (1970). White spots in tuberous sclerosis. Journal of Pediatrics, 77, 587-594.

Lagos, J. C., and Gomez, M. R. (1967). Tuberous sclerosis: reappraisal of a clinical entity. Mayo Clinic Proceedings, 42, 26-49.
Pampiglione, G. (1956). Some anatomical considerations upon electrode placement in routine EEG. Proceedings Electro. Physiol. Technol. Ass., 7, 1-20.

Pampiglione, G. (1966). Normal and abnormal coordination of movements: a poly-myographic approach. Journal of the Neurological Sciences, 3, 525-538.

Pampiglione, G., Evans, P. R, Harris, R., and Moynahan, E. J. (1968). Aspetti elettroclinici della Sclerosi Tuberosa. In Atti delle Conferenze di aggiornamento Società Italiana EEG, pp. 73-85. Gaggi: Bologna.

Pampiglione, G., and Pugh, E. (1975). Infantile spasms and subsequent appearance of tuberous sclerosis syndrome. Lancet, 2, 1046.

Pellizzi, G. B. (1900). Studi Clinici e Anatomo Patologici sull Idiozia. Annali di Freniatria, 10, 61-139; 193-224; 293-326; (1901). 11, 1-34; 97-316; 193-224; 289-316.

Pellizzi, G. B. (1901). Contributo allo studio dell idiozia. Rivista Sperimentale di Freniatria, (1901). 27, 265-269.

Pellizzi, G. B. (1901). Contributo alla istologia ed alla patogenesi dei Tumori di Tessuto nervoso. Rivista Sperimentale di Freniatria, 27, 957-995.

Ross, A. T., and Dickerson, W. W. (1943). Tuberous sclerosis. Archives of Neurology and Psychiatry, 50, 233-257.

Sherlock, E. B. (1911). The Feeble Minded. Macmillan: London.

Taylor, D. C., Falconer, M. A., Bruton, C. J., and Corsellis, J. A. M. (1971). Focal dysplasia of the cerebral cortex in epilepsy. Journal of Neurology, Neurosurgery, and Psychiatry, 34, 369-387.

Tilgen, W. (1973). Zur Ultrastruktur der sogenamten 'White leaf-shaped macules' bei der Tuberösen Hirnsklerose Bourneville-Pringle. Archiv für Dermatologie Forschung, 248, 13-27.

West, W. J. (1840-1841). On a peculiar form of infantile convulsions. Lancet, 1, 724.

Wilson, S. A. K. (1940). Neurology. Arnold: London.

Zaremba, J. (1968). Tuberous sclerosis: a clinical and genetic investigation. Journal of Mental Deficiency Research, 12, 63-80 